\title{
$O$-Succinylhomoserine as an Intermediate in the Synthesis of Cystathionine by Escherichia coli
}

\author{
By R. J. ROWBURY AND D. D. WOODS \\ Microbiology Unit, Department of Biochemistry, University of Oxford, \\ and Department of Botany, University College, University of London
}

(Received 25 March 1964)

\begin{abstract}
SUMMARY
Further evidence that cystathionine is a precursor of methionine synthesis in Escherichia coli was obtained by showing its synthesis by cellfree extracts of an auxotroph which required homocysteine or methionine for growth. Succinate, as well as homoserine and cysteine, was an obligatory substrate and maximal synthesis was dependent on the further addition of glucose, adenosine triphosphate and coenzyme $\mathbf{A}$. The reaction was further studied by using mixtures of extracts of auxotrophs of which each alone was unable to synthesize cystathionine. At least two enzymes were required: the first, present in one strain, formed a heat-stable intermediate from homoserine and succinate; while the second, present in the other strain, converted this intermediate to cystathionine in the presence of cysteine. The intermediate was formed enzymically from homoserine and succinyl-coenzyme $\mathbf{A}$ alone and was ninhydrin-positive; this suggested that it might be $O$-succinylhomoserine. This compound was prepared by reaction of succinyl chloride or succinic anhydride with homoserine in the presence of perchloric acid; its chromatographic and chemical properties were closely similar to those of the intermediate. The synthetic product, like that formed enzymically, gave cystathionine when incubated with cysteine and a cell-free extract of the relevant $\boldsymbol{E}$. coli auxotroph. It is concluded that $\boldsymbol{O}$-succinylhomoserine is an intermediate in the formation of cystathionine, and consequently of methionine by $E$. coli.
\end{abstract}

\section{INTRODUCTION}

The properties of the various auxotrophic strains of Escherichia coli which give a growth response with methionine strongly suggest that this amino acid arises from homoserine+cysteine with the intermediate formation of cystathionine and homocysteine (see review by Davis, 1955). This role of homocysteine has been amply confirmed with suspensions of intact organisms and with cell-free enzyme preparations (Gibson \& Woods, 1960; Guest, Helleiner, Cross \& Woods, 1960). In the case of cystathionine closer investigation has given apparently contradictory results. It was established that extracts of many strains of $\boldsymbol{E}$. coli contained an enzyme, cystathionase, which catalysed the formation of homocysteine from cystathionine (Wijesundera \& Woods, 1953, 1962); the probable physiological significance of this enzyme in methionine synthesis was emphasized by the fact that its formation was repressed by methionine, the ultimate product of the reaction sequence (Rowbury \& Woods, 1961 $b, 1964)$. On the other hand, the work of Bolton, Cowie \& Sands (1952) with growing cultures of $\boldsymbol{E}$. coli cast doubt on cystathionine as an inter- 
mediate since it did not, as would be expected, decrease the incorporation into bacterial protein of $\left[{ }^{35} \mathrm{~S}\right]$-sulphate added to the medium. While these results might be explained either by a relative impermeability of the organism to cystathionine or by lack of equilibration of free cystathionine with enzyme-bound cystathionine within the organism, the case for cystathionine would clearly be strengthened if the organism were found to contain enzymes for its synthesis from the presumed precursors as well as the enzyme already demonstrated for its conversion to the next intermediate.

An auxotrophic strain of Escherichia coli known to lack cystathionase was chosen initially for the investigation since it would not be able to degrade any cystathionine formed. The trial of succinate as co-substrate with homoserine and cysteine was prompted by a brief report (Davis, Kornberg, Nagler, Miller \& Mingioli, 1959) that certain succinate-requiring mutants of $\boldsymbol{E}$. coli grew in absence of succinate when provided with a mixture of methionine +lysine +threonine. This suggested that succinate might be a reactant at some stage of the synthesis of each of these amino acids. Furthermore, correlation of the nutritional and genetic properties of methionine auxotrophs of Neurospora crassa (Buss, 1944) and Salmonella typhimurium (Smith, 1961) indicated that more than one enzyme was concerned in cystathionine synthesis from homoserine and cysteine. Brief reports of part of the present work were given by Rowbury (1961, 1962b).

\section{METHODS}

Organisms and enzyme extracts. All the auxotrophic strains of Escherichia coli used in this work were maintained on slopes of Oxoid nutrient agar, subcultured monthly and stored at $4^{\circ}$ after incubation for $18 \mathrm{hr}$ at $37^{\circ}$. Strain 26/18 responded to homocysteine or methionine and the following strains responded also to cystathionine: $122 / 33,2 / 2,7 / 9,6 / 5,7 / 17$ G, 2/17, 8/15. Strain B 184 grew with homoserine or with methionine + threonine. Strain $122 / 33$, derived from $E$. coli w, was provided by Dr B. D. Davis and в 184 (from $E$. coli B) by Dr J. S. Gots; the remaining strains were isolated in this laboratory after ultraviolet (u.v.)-irradiation of the parent strain $E$. coli 518 (ATCC 9723).

Organisms were grown on the glucose lactate salts medium (GL) of Guest $e t$ al. (1960) supplemented with DL-homocysteine $(0.25 \mathrm{~mm})$. Conditions of growth and harvesting and the methods used for the preparation and subsequent treatment of cell-free extracts were as described by Rowbury \& Woods (1961a).

Study of cystathionine formation. The basal reaction mixture (solution $A$ ) normally contained (mM in $3 \mathrm{ml}$. of $\mathbf{8 0} \mathrm{mm}$-potassium phosphate buffer, $\mathrm{pH} 7 \cdot 5$ ): DL-homoserine, 5 ; L-cysteine, 3.3; sodium succinate, 50; adenosine triphosphate, $3 \cdot 3$; glucose, $6 \cdot 6$; coenzyme A, 0.06. After addition of the enzyme preparation (equivalent to $3.3 \mathrm{mg}$. protein $/ \mathrm{ml}$.) the tubes were incubated in air at $37^{\circ}$ for 3-4 $\mathrm{hr}$. The reaction was terminated by heating at $100^{\circ}$ for $3 \mathrm{~min}$. and cystathionine assayed in the supernatant fluid obtained after centrifugation.

Microbiological assays. A strain of Escherichia coli (122/33) giving a growth response with cystathionine was used for the estimation of this amino acid. Medium $G L$ was used, with DL-cystathionine as standard. The tubes $(150 \times 20 \mathrm{~mm}$. containing $4 \mathrm{ml}$. medium) were incubated in a sloped position in air at $37^{\circ}$ for $40 \mathrm{hr}$ and the 
amount of growth was assessed in a Spekker Photoelectric Absorptiometer H760 (Hilger \& Watts, London) with $0.5 \mathrm{~cm}$. light cells. The shape of the curve relating dosage to response to pure cystathionine (Fig. 1) was similar with typical experimental samples. The assay organism responds also to homocysteine and methionine, but in experiments on cystathionine formation by extracts of $E$. coli 26/18 these amino acids were shown to be absent by independent assays (Table 1). In experiments in which extracts of $E$. coli strains 7/9 and 2/2 were used as enzyme source it was possible that any cystathionine formed would be converted wholly or in part to homocysteine since both these organisms contain cystathionase. The assay was not, however, invalidated since homocysteine, and mixtures of homocysteine + cystathionine give quantitatively the same response as cystathionine itself (Fig. 1). Furthermore, methionine is not formed from homocysteine by extracts of those organisms under the conditions of the test for cystathionine synthesis. The results are therefore expressed throughout in terms of cystathionine.

The procedure for the estimation of homoserine and homocysteine was similar to that for cystathionine except that the assay organisms were, respectively, Escherichia coli $\mathrm{B} 184$ and $E$. coli 26/18. Methionine was assayed with Streptococcus equinus $\mathrm{P} 60$ as described by Gibson \& Woods (1960).

Estimation of succinic acid. This was titrated with $0.01 \mathrm{~m}$-barium hydroxide after evaporating to dryness the fraction eluted from columns of Dowex-1 resin with $6 \mathrm{~N}$-formic acid.

Chromatography on paper. For the separation and identification of cystathionine, chromatograms were developed on Whatman no. 1 paper with $n$-butanol + acetic acid + water $(2+1+1$, by vol.). When cystathionine was to be assayed, the chromatograms were dried for $2 \mathrm{hr}$ at $100^{\circ}$ and the relevant regions eluted with water. Homoserine and $\boldsymbol{O}$-succinylhomoserine were separated from one another either by the above solvent mixture or by $n$-butanol + propionic acid + water $(47+22+31$, by vol.) Amino acids were detected by spraying with ninhydrin $(0 \cdot 2 \%, \mathrm{w} / \mathrm{v}$, in $n$-butanol saturated with water) and heating at $80^{\circ}$ for $10 \mathrm{~min}$. Succinic acid was detected with bromocresol green (0.04\% solution in water adjusted to $\mathrm{pH} 7 \cdot 5$.)

In some experiments with isotopically-labelled succinate the chromatograms were either scanned directly or the material eluted by water from specific regions counted after spreading on metal or glass discs. A mica end-window Geiger-Müller tube (General Electric Co. type 2B 2) was used in conjunction with a Scaler 1700 of Isotope Developments Ltd. Reading, Berks.

Column chromatography. In the earlier part of the work the resin used was Dowex-50 (H form, $\times 4,200-400 \mathrm{mesh}$ ) and the procedure that of Wall (1953). Experimental samples in $\mathrm{N}-\mathrm{HCl}$ were placed on $30 \times 0.9 \mathrm{~cm}$. columns and the amino acids eluted with $\mathrm{N}-\mathrm{HCl}$, separate fractions being collected. Smaller columns were used $(5 \times 0.9 \mathrm{~cm}$.) when the object was only to free the samples from succinate; these were applied in neutral solution and, after washing the column thoroughly to remove succinate, the mixed amino acids were removed with $\mathrm{N}-\mathrm{HCl}$.

In other experiments, Dowex-1 resin (acetate form, $\times 8,200-400$ mesh) was used. Samples in aqueous solution were applied to a previously washed column $(18 \times \mathbf{0 . 9}$ cm.) that was then eluted with $15 \mathrm{ml}$. water followed by $0.2 \mathrm{~N}$-acetic acid.

Fractions of eluates from both types of column were assayed for amino- $\mathrm{N}$ by using the modified ninhydrin reagent of Moore \& Stein (1954); $\mathrm{HCl}$ was removed 
from fractions to be tested for biological activity by evaporating to dryness in a small rotary evaporator.

Chemicals. Coenzyme A was a product of the Sigma Chemical Company (St Louis, Mo., U.S.A.) and a solution of succinyl-coenzyme A was prepared from it by the method of Simon \& Shemin (1953) immediately before use. Succinic anhydride $\left(0.1 \mathrm{M} ; 0.25 \mathrm{ml}\right.$.) was added to the coenzyme $\left(15 \mathrm{mg}\right.$. in $2 \mathrm{ml}$. of water at $\left.0^{\circ}\right)$ and the mixture stood at $0^{\circ}$ for $20 \mathrm{~min}$. after adjustment to $\mathrm{pH} 7 . \quad\left[{ }^{14} \mathrm{C}_{2,3}\right]$-Succinic acid was obtained from the Radiochemical Centre, Amersham, Bucks.

The sources of other special chemicals were as described by Rowbury \& Woods $(1961 a, 1964)$.

\section{Table 1. Differential microbiological assay of the products formed} by cell-free extracts of Escherichia coli $26 / 18$

Ultrasonic extract (equiv. $3.3 \mathrm{mg}$. protein $/ \mathrm{ml}$.) was incubated for $4 \mathrm{hr}$ in solution $A$ with the stated omissions. A control in which the complete reaction mixture was heated for $3 \mathrm{~min}$. at $100^{\circ}$ before incubation gave values not exceeding $0.05 \mu \mathrm{mole}$ in any case; the appropriate value has been deducted from the results given.

\begin{tabular}{|c|c|c|c|}
\hline & & Assay organism & \\
\hline & $\begin{array}{l}\text { E. coli } \\
122 / 33\end{array}$ & $\begin{array}{c}\text { E. coli } \\
26 / 18\end{array}$ & $\begin{array}{l}\text { Streptococcus } \\
\text { equinus } \mathbf{P} 60\end{array}$ \\
\hline & & Product assayed & \\
\hline & $\begin{array}{c}\text { Cystathionine } \\
+ \\
\text { homocysteine } \\
+ \\
\text { methionine }\end{array}$ & $\begin{array}{c}\text { Homocysteine } \\
+ \\
\text { methionine }\end{array}$ & Methionine \\
\hline $\begin{array}{l}\text { Omissions from } \\
\text { solution } A\end{array}$ & & duct formed $(\mu \mathrm{n}$ & \\
\hline None & $1 \cdot 39$ & 0.04 & $0 \cdot 00$ \\
\hline Homoserine & $0 \cdot 11$ & 0.06 & 0.00 \\
\hline Cysteine & $0 \cdot 15$ & 0.03 & 0.01 \\
\hline
\end{tabular}

\section{RESULTS}

Cystathionine formation by Escherichia coli 26/18

This auxotroph lacks the cystathionase enzyme and therefore responds only to homocysteine or methionine; it was assumed that it would retain the ability to synthesize cystathionine. Unsuccessful attempts had been made earlier to demonstrate this with intact organisms and with cell-free preparations and the indicated precursors (homoserine + cysteine) in the presence of various mixtures of possible energy sources and cofactors (e.g. glucose, adenosine triphosphate (ATP), coenzyme A, pyridoxal phosphate). However, the further addition of succinate to unpurified ultrasonic extracts incubated in a mixture of all the above substances led to the production of material which supported the growth of $E$. coli 122/33, an auxotroph which responds to cystathionine as well as to homocysteine and methionine. Concurrent assay of the reaction products with Streptococcus equinus $\mathrm{P} 60$ (which responds only to methionine) and $E$. coli $26 / 18$ itself (which responds only to homocysteine and methionine) showed that very little methionine or homocysteine was 
present (Table 1); they accounted, at most, for only about $5 \%$ of the growth response given by $E$. coli $122 / 33$ and cystathionine was therefore indicated as the major product. The reaction products were also assayed with this organism after chromatography on paper with $n$-butanol + acetic acid + water and eluting separate regions of the chromatogram (Fig. 2). The active reaction product had a similar $\boldsymbol{R}_{F}$ value to cystathionine, which was clearly distinguishable from those for methionine and homocysteine. Homocysteine was partly oxidized to homocystine and gave two active regions on the chromatogram. It was concluded provisionally that the product was cystathionine.

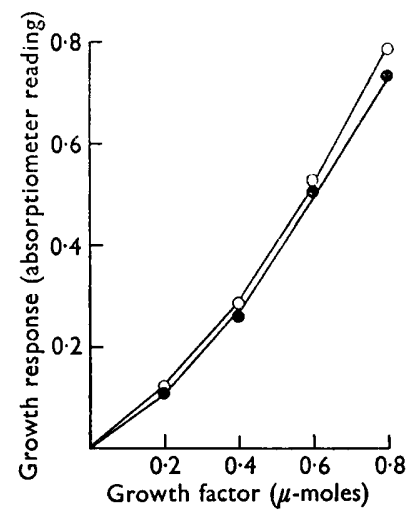

Fig. 1

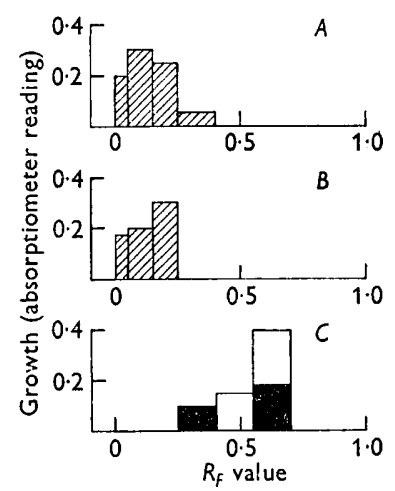

Fig. 2

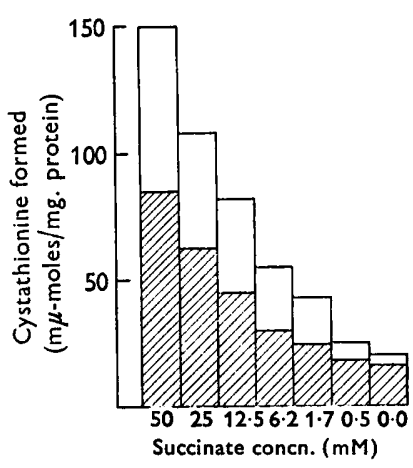

Fig. 3

Fig. 1. Growth response of Escherichia coli 122/33 to cystathionine (O) and homocysteine (O).

Fig. 2. Identification of cystathionine by paper chromatography followed by microbiological response to Escherichia coli 122/33. Extract of $E$. coli 26/18 was incubated for $3 \mathrm{hr}$ in solution $A$ and the de-proteinized products chromatographed with $n$-butanol + acetic acid + water. After $20 \mathrm{hr}$, regions of the chromatogram were eluted with water and assayed with $E$. coli 122/33 (A). Pure specimens of cystathionine $(B)$ and homocysteine and methionine $(C)$ were given the same overall treatment.

Fig. 3. Effect of succinate and coenzyme $A$ on cystathionine formation. Ultrasonic extract of Escherichia coli 26/18 was incubated for $4 \mathrm{hr}$ in solution $A$ (with and without coenzyme A) containing the stated concentrations of succinate. With coenzyme A, open; without coenzyme A. hatched.

Requirements for cystathionine formation. Optimal synthesis of cystathionine occurred with dialysed, though otherwise unpurified, ultrasonic extracts of the organism in a reaction mixture (solution $A$, see Methods section) containing homoserine, cysteine, succinate, glucose, ATP and coenzyme A. Synthesis was decreased by $\mathbf{8 0 - 9 0 \%}$ when homoserine and/or cysteine were omitted (Table 2); the residual formation may have been due to sources of these amino acids in the enzyme preparation. A small amount of cystathionine was formed when homoserine was replaced by aspartic acid, which is known to be its precursor in Escherichia coli (Hirsch \& Cohen, 1954).

Omission of succinate also decreased cystathionine formation by $80-90 \%$ (Table 2; Fig. 3). Synthesis increased with increasing succinate concentration up to $50 \mathrm{~mm}$, which was the highest value tested (Fig. 3). Of a number of substances structurally or metabolically related to succinate, only $\alpha$-oxoglutarate, which had 
about half the activity of succinate, replaced it to any significant extent; fumarate, malate, citrate, acetate and acetyl-coenzyme $A$ were essentially inactive. The effect of omitting coenzyme $\mathbf{A}$ from the reaction mixture was tested over a range of concentrations of succinate (Fig. 3); in each case cystathionine formation was decreased about twofold. The effect of coenzyme $\mathbf{A}$ was only slightly sharpened by treatment of the enzyme preparation with Dowex-1 resin; it seems probable that bound forms were present. The results suggest that succinate may act in cystathionine formation after prior conversion to succinyl-coenzyme $\mathbf{A}$.

\section{Table 2. Cystathionine formation by extracts of Escherichia coli 26/18}

Ultrasonic extract was incubated for $3 \mathrm{hr}$ in solution $A$, modified as indicated; aspartate and pyridoxal phosphate were 5.0 and $0.5 \mathrm{~mm}$, respectively. - , Indicates no addition or omission.

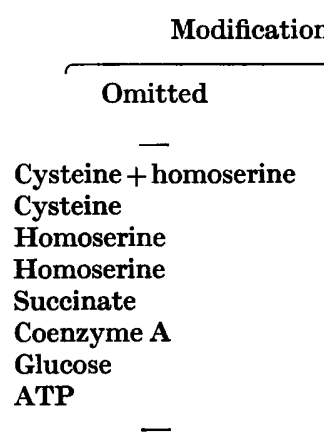

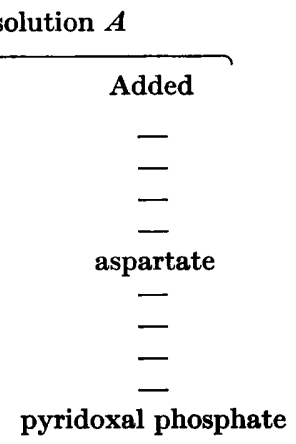

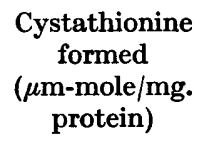
formed ( $\mu \mathrm{m}-\mathrm{mole} / \mathrm{mg}$. protein)

190

10

22

18

50

25

100

42

31

195

Optimal synthesis of cystathionine also required the presence of glucose (replaceable by hexose diphosphate) + ATP, presumably as components of an energygenerating system (Table 2). It is unlikely therefore that succinate acts as a source of energy, and a more specific role is indicated.

Pyridoxal phosphate had no effect on cystathionine formation under the usual test conditions nor when the dialysed enzymic extracts had been further treated with Dowex-1 resin. If it is the prosthetic group of any of the enzymes concerned in the present amino acid transformations it is clear that it is not readily dissociated.

Kinetics. The reaction was optimal at $\mathrm{pH} 7 \cdot 5$, cystathionine formation being decreased to $40 \%$ and $80 \%$ of the optimum value at $\mathrm{pH} 6.9$ and $8 \cdot 0$, respectively. With all the required accessory substances present there was a linear relationship between time and amount of product formed up to $2 \mathrm{hr}$; appreciable formation occurred for a further $3 \mathrm{hr}$.

\section{Cystathionine formation by mixed extracts of cystathionine-requiring mutants}

The results so far reported suggested that there is more than one enzymic step in the overall formation of cystathionine from homoserine, cysteine and succinate. It is possible that auxotrophs which fail to synthesize cystathionine might lack different enzymes, and consequently that a mixture of extracts from appropriate auxotrophs might achieve the synthesis, one extract providing the enzyme or enzymes missing from the other. This proved to be the case (Table 3); in a survey of six auxotrophs of Escherichia coli of this type the extract of one of them (strain 2/2) 
was effective in admixture with extract of any of three other strains (7/9,6/5 and $7 / 17 \mathrm{G})$, but not with the other two. As expected all the individual extracts were inactive. Since all these auxotrophs contain cystathionase, the product assayed was probably a mixture of cystathionine and homocysteine. For reasons stated in the Methods section the results may legitimately be given in terms of cystathionine.

\section{Table 3. Formation of cystathionine by mixtures of extracts of various cystathionine-requiring auxotrophs of Escherichia coli}

Ultrasonic extract (equiv. $3 \cdot 3 \mathrm{mg}$. protein $/ \mathrm{ml}$.) of the stated auxotroph was incubated for $4 \mathrm{hr}$ in solution $A$ with and without extract of auxotroph 2/2 (equiv. 3.3 $\mathrm{mg}$. protein/ ml.)

$\begin{array}{ccc}\begin{array}{c}\text { Extract derived } \\ \text { from } E \text {. coli } \\ \text { strain no. }\end{array} & \begin{array}{c}\begin{array}{c}\text { Cystathionine formed } \\ (\mu \mathrm{m} \text {-mole/mg. protein) with }\end{array} \\ \text { extract of } E \text {. coli } \text { strain } 2 / 2\end{array} \\ 2 / 2 & - & \text { Present } \\ 7 / 17 \text { G } & 5 & 0 \\ 6 / 5 & 5 & 104 \\ 2 / 17 & 6 & 100 \\ 7 / 9 & 8 & 6 \\ 8 / 15 & 5 & 126\end{array}$

Table 4. Cystathionine formation by a mixture of extracts of Escherichia coli strains $7 / 9$ and $2 / 2$

Ultrasonic extracts (equiv. $5 \mathrm{mg}$. protein of each strain) were incubated together in $3 \mathrm{ml}$. of solution $\boldsymbol{A}$ with the stated omissions. Pyridoxal phosphate, 0.5 mM.

$\quad$ Omission from solution $\boldsymbol{A}$
None
Homoserine
Cysteine
Succinate
Glucose + ATP
None (pyridoxal phosphate added)

\begin{tabular}{|c|}
\hline $\begin{array}{c}\text { Cystathionine } \\
\text { formed } \\
\text { ( } \mu \text { m-mole } / \mathrm{mg} \text {. } \\
\text { protein) }\end{array}$ \\
\hline 160 \\
\hline 12 \\
\hline 15 \\
\hline 20 \\
\hline 15 \\
\hline 160 \\
\hline
\end{tabular}

The active mixture of extracts from strains $2 / 2$ and $7 / 9$ was selected for detailed investigation. Homoserine, cysteine, succinate and an energy source were required for significant formation of cystathionine (Table 4), thus confirming that the reaction under study was similar to that catalysed by the competent strain 26/18. Pyridoxal phosphate was again without effect. Information about the probable order of action of the enzyme or enzymes present in each extract was obtained from experiments in which only one extract was added initially and the other about halfway through the period of incubation (Table 5). It is clear that strain 7/9 acted first and that an intermediate compound accumulated which was converted to cystathionine either by enzymes of strain $2 / 2$ alone or by these + other enzymes from strain $7 / 9$.

Nature of the first reaction. The particular substrates required for the two steps in cystathionine formation were determined in further two-part experiments in which 
extract of strain 7/9 was always used in the first incubation but various mixtures of the three substrates were added either during the first or second period of incubation (Table 6). Maximum synthesis of cystathionine was obtained when homoserine + succinate + extract of strain $7 / 9$ were present initially and cysteine + extract of strain 2/2 was added later. Under all other conditions, except the control in which all three substrates were present from the beginning, synthesis was low. These results strongly suggest that an intermediate formed from homoserine and succinate by the enzymes of strain 7/9 was converted to cystathionine in the presence of cysteine by an enzyme or enzymes from strain $2 / 2$.

Table 5. Cystathionine formation by mixed cell-free extracts : sequence of action

Ultrasonic extracts of Escherichia coli strains 7/9 and 2/2 (each equiv. $5 \mathrm{mg}$. protein/ $3 \mathrm{ml}$.) were added as indicated to solution $A$, either initially or after incubation for $2.5 \mathrm{hr}$; total time of incubation $4 \mathrm{hr}$.

$\begin{array}{llc}\text { Source of extract added } & \text { After } 2 \cdot 5 \mathrm{hr} & \begin{array}{c}\text { Cystathionine } \\ \text { formed } \\ (\mu \mathrm{m} \text {-mole/mg. } \\ \text { protein })\end{array} \\ \text { Bnitially } & - & 124 \\ \text { Strain } 7 / 9 & \text { Strain } 2 / 2 & 135 \\ \text { Strain } 2 / 2 & \text { Strain } 7 / 9 & 46 \\ \text { Nil } & \text { Both strains } & 21\end{array}$

Table 6. Cystathionine formation by mixed extracts: order of utilization of the substrates

Homoserine, cysteine and succinate were added as indicated to the other components of the solution $\dot{A}$, either initially or after incubation for $2.5 \mathrm{hr}$. Extract of Escherichia coli strain $7 / 9$ was added initially and that of $E$. coli strain $2 / 2$ at $2.5 \mathrm{hr}$; each were equiv. $5 \mathrm{mg}$. protein/3 ml. Total time of incubation $4 \mathrm{hr}$.

\begin{tabular}{|c|c|c|}
\hline \multicolumn{2}{|c|}{ Substrate added } & \multirow{2}{*}{$\begin{array}{c}\text { Cystathionine } \\
\text { formed } \\
(\mu \mathrm{m} \text {-mole } / \mathrm{mg} \text {. } \\
\text { protein) }\end{array}$} \\
\hline Initially & Added 2.5 hr & \\
\hline Homoserine + succinate + cysteine & - & 124 \\
\hline Homoserine + succinate & Cysteine & 203 \\
\hline Succinate & Homoserine + cysteine & 57 \\
\hline Cysteine + succinate & Homoserine & 51 \\
\hline Homoserine & Cysteine + succinate & 40 \\
\hline Cysteine & Homoserine + succinate & 20 \\
\hline Homoserine + cysteine & Succinate & 34 \\
\hline Nil & Homoserine + succinate + cysteine & 20 \\
\hline
\end{tabular}

Heat-treatment of the reaction mixture at the end of the first incubation to inactivate the enzymes present in extract of strain $7 / 9$ did not significantly decrease the yield of cystathionine on further addition of cysteine + extract of strain $2 / 2$ (Table 7). No enzyme uniquely present in strain $7 / 9$ was therefore required for the second reaction in addition to enzymes present in strain 2/2. The intermediate compound was moderately stable to heat; similar results were obtained with 2 min. at $100^{\circ}$, though longer periods at this temperature were detrimental. 


\section{Nature of the intermediate compound}

Preparations of the intermediate were obtained by incubating ultrasonic extracts of Escherichia coli $7 / 9$ in the usual reaction mixture (solution $A$ ) but without cysteine. The intermediate was detected and assayed biologically by measuring cystathionine formation when samples were incubated with ultrasonic extracts of strain $2 / 2$ and a buffered reaction mixture containing cysteine + glucose + ATP, i.e. solution $A$ from which homoserine, succinate and coenzyme $\mathbf{A}$ had been omitted.

\section{Table 7. Effect of mild heat-treatment on the intermediate compound}

Extract of Escherichia coli strain $7 / 9$ was incubated with solution $\boldsymbol{A}$ (cysteine omitted) for $2.5 \mathrm{hr}$; extract of $E$. coli strain $2 / 2$ + cysteine were then added and incubation continued for a further $1.5 \mathrm{hr}$. The reaction mixtures were heated as indicated.

$\begin{array}{cc}\text { Heat-treatment } & \begin{array}{c}\text { Cystathionine } \\ \text { formed } \\ (\mu \mathrm{m} \text {-mole/mg. } \\ \text { protein) }\end{array} \\ \text { None } & 112 \\ \mathbf{5 5}^{\circ} \text { for } 2 \text { min. initially } & 14 \\ \mathbf{5 5}^{\circ} \text { for } 2 \text { min. at } \mathbf{2 . 5} \mathrm{hr} . & \mathbf{9 6} \\ \mathbf{5 5}^{\circ} \text { for } 10 \text { min. initially } & 7 \\ \mathbf{5 5}^{\circ} \text { for } 10 \text { min. at } \mathbf{2 . 5} \mathrm{hr} . & \mathbf{9 8}\end{array}$

Separation by chromatography. Paper chromatograms of samples of the untreated reaction products were developed with $n$-butanol + propionic acid + water solvent; comparison with the initial reaction mixture showed the presence of a new ninhydrin-positive compound of $\boldsymbol{R}_{F}$ value $\mathbf{0 . 3 5}$ as compared with $\mathbf{0 \cdot 2 7}$ for homoserine. The colour obtained with ninhydrin on paper was initially yellow-brown with this new compound. It was not present when either homoserine or succinate was omitted from the original reaction mixture. Several amino acids metabolically related to homoserine or succinate were clearly separated from this material on the chromatogram.

The intermediate compound was also separated from the reaction mixture by chromatography on columns of Dowex-50 resin. Unchanged succinate was not bound and was washed through with water. Homoserine and the presumed intermediate were eluted by $\mathrm{N}-\mathrm{HCl}$; an almost complete separation was obtained on a $30 \mathrm{~cm}$. column (Fig. 4). The colour given by ninhydrin in tests in solution was similar to that of homoserine (which was used as standard in the amino-N determinations) and not the yellow brown obtained in the test on dried paper. Pooled fractions covering the regions of the two peaks were evaporated to dryness, redissolved and tested separately for conversion to cystathionine in the presence of the enzyme preparation from strain $2 / 2$; only the second component eluted was active in this sense and chromatography on paper showed that only it contained the ninhydrin-positive material of $\boldsymbol{R}_{F}$ value $\mathbf{0 \cdot 3 5}$. It was concluded that this material was the intermediate compound.

Stability to acid and alkali. Unpurified reaction mixtures containing the intermediate compound were adjusted to various $\mathrm{pH}$ values, incubated at $37^{\circ}$ for $5 \mathrm{~min}$. and re-adjusted to $\mathrm{pH} 7 \cdot 5$. The amount of intermediate which survived was assayed 
enzymically with extract of strain $2 / 2$ as described above (Fig. 5). The intermediate compound was highly unstable above $\mathrm{pH} 8$ and was almost completely destroyed at $\mathrm{pH} 11$.

Although the intermediate was relatively stable to mild acid treatment at $37^{\circ}$ (Fig. 5), all activity was lost by heating for $2 \mathrm{hr}$ with $\mathrm{N}-\mathrm{HCl}$ at $100^{\circ}$. Material purified by chromatography on Dowex-50 resin was used in these experiments. The presence of homoserine and succinate in the products of acid-treatment (presumably hydrolysis) was shown by paper chromatography; homoserine was also detected by the growth response of Escherichia coli в 184, a homoserine auxotroph.

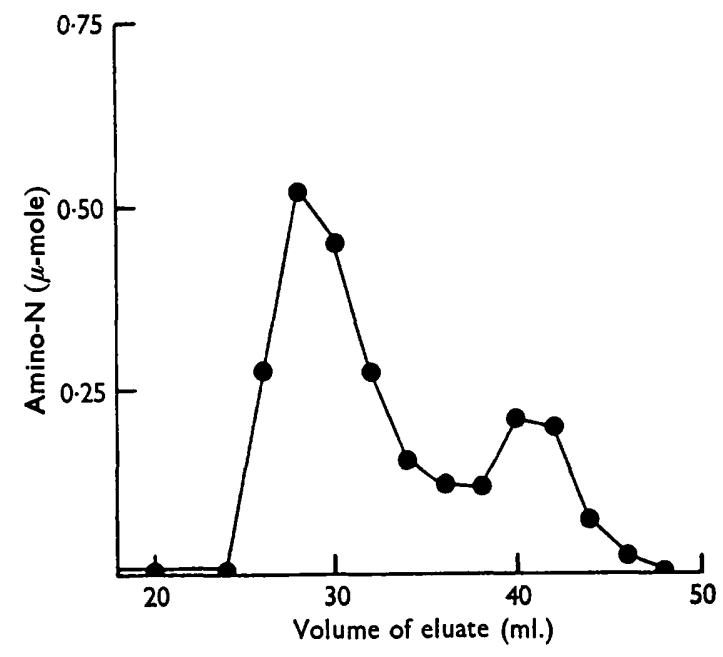

Fig. 4

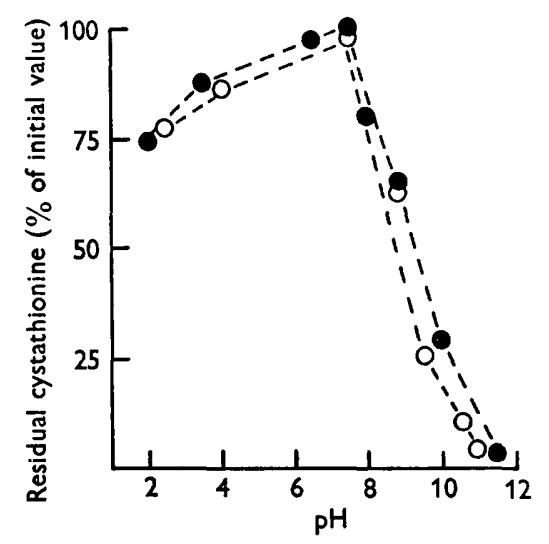

Fig. 5

Fig. 4. Chromatographic separation of the intermediate from homoserine. Extract of Escherichia coli $7 / 9$ was incubated for $4 \mathrm{hr}$ in solution $A$ (omitting cysteine). The deproteinized products were concentrated in vacuo and chromatographed on Dowex-50 resin as described in the Methods section. Fractions of the eluate were assayed for amino-N.

Fig. 5. The effect of treatment with mild acid and alkali on the intermediate and its synthetic counterpart. Unpurified reaction mixtures containing the intermediate were incubated at the stated $\mathrm{pH}$ value for $5 \mathrm{~min}$. at $37^{\circ}$, readjusted to $\mathrm{pH} \gamma \cdot 5$ and the residual intermediate assayed (as cystathionine) after incubation with cysteine and extract of Escherichia coli 2/2. A synthetic preparation of $O$-succinylhomoserine was similarly treated. 0 , intermediate formed enzymically; $O$, synthetic product.

Incorporation of radioactive succinate. The results so far recorded suggested that the intermediate was a derivative of succinic acid. Confirmation of this was sought by experiments in which enzymic synthesis of the intermediate took place in the presence of $\left[{ }^{14} \mathrm{C}_{2,3}\right]$-succinate, which was added ( $5 \mu \mathrm{C} / 3 \mathrm{ml}$.) to the reaction mixture. The unpurified products of the reaction were placed on a short column of Dowex-50 resin and unchanged succinate removed by passing water through until the washings showed no radioactivity. Amino acids, which include the intermediate compound, were eluted with $\mathrm{N}-\mathrm{HCl}$ and samples were assayed for content of ${ }^{14} \mathrm{C}$; five times as much isotope was incorporated when homoserine was present in the initial reaction mixture than when it was absent. Samples of the eluate chromatographed on paper 
(solvent, $n$-butanol + propionic acid + water) showed a radioactive region with an $\boldsymbol{R}_{\mathrm{F}}$ value about $\mathbf{0 . 3 5}$ (Fig. 6), corresponding with the $\boldsymbol{R}_{\mathrm{F}}$ value of the intermediate compound with this solvent. The small amount of radioactivity of $R_{\mathrm{F}} 0.7$ was due to succinate which may have been formed by decomposition of some of the intermediate, or have escaped removal during the treatment with Dowex resin. When the amino acid fraction was treated with hot acid before running the chromatogram, the bulk of the radioactivity now appeared at $\boldsymbol{R}_{\mathrm{F}} \mathbf{0 \cdot 7}$ (corresponding with succinate) and only traces at $\boldsymbol{R}_{\mathbf{F}} \mathbf{0 \cdot 3 5}$ (Fig. 6 ).

In one experiment a comparison was made in molar terms between the amount of homoserine used, the amount of intermediate compound formed (in terms of cystathionine formed enzymically from it) and the amount of succinate incorporated into the amino acid fraction. The concentration of DL-homoserine in the usual reaction mixture was decreased to $1.7 \mathrm{~mm}$ and the succinate contained $5 \mu \mathrm{C}$ of the isotopically labelled compound. The amount of homoserine present was assayed microbiologically before and after incubation for $2.5 \mathrm{hr}$; other samples were used for the enzymic assay of the intermediate. The amount of succinate incorporated was calculated from the radioactivity of the material eluted by $\mathrm{N}-\mathrm{HCl}$ from a Dowex-50 column (washed to remove unchanged succinate) which had been loaded with the remainder of the incubated reaction mixture. The amount of homoserine metabolized was $0.58 \mu$ mole; $0.54 \mu$ mole of the intermediate were formed and $0 \cdot 49 \mu$ mole of succinate were incorporated. It was likely therefore that the intermediate contained one homoserine and one succinate residue; the slightly low result obtained for succinate may have resulted from losses during the resin treatment since the other two values were derived from direct assays of the untreated reaction products.

\section{The role of succinyl-coenzyme $A$}

Coenzyme $\mathbf{A}$ increased the overall synthesis of cystathionine from homoserine + succinate + cysteine by enzyme preparations of Escherichia coli 26/18 (Fig. 3). Succinate was found above to be required only in the reaction leading to the formation of the intermediate compound from homoserine; it was possible therefore that it was first converted to succinyl-coenzyme $\mathbf{A}$ by a succinyl-coenzyme $\mathbf{A}$ synthetase also present in the extracts of strain $7 / 9$ which formed the intermediate. In the following experiments formation of the intermediate was studied with an extract of $E$. coli strain $7 / 9$ that had been stored at $-15^{\circ}$ for 30 days and had lost $60 \%$ of its activity.

Addition to the reaction mixture of a purified preparation of succinyl-coenzyme A synthetase derived from Rhodopseudomonas spheroides (Burnham, 1963; kindly provided by Dr B.F. Burnham) increased twofold the formation of the intermediate. It is likely therefore that Escherichia coli contains this enzyme and that it decays more rapidly than the other enzymes concerned in cystathionine synthesis. Succinyl-coenzyme A prepared chemically was tested by the usual two-stage incubation method in which the intermediate compound formed by extract of $E$. coli strain 7/9 was later converted to cystathionine in the presence of cysteine + extract of strain 2/2. Four times as much cystathionine was formed with succinylcoenzyme A than with succinate + coenzyme A (compare Expt. 1 and 2, Table 8). Furthermore, the addition of glucose + ATP could be deferred until the second 
stage of the incubation without seriously diminishing the amount of cystathionine finally produced (Expt. 3). This means that although an energy source was required for the reaction between the intermediate and cysteine (compare Expt. 3 and 4) it was not required for that between homoserine and succinyl-coenzyme $A$ to form the intermediate. The latter reaction proceeds satisfactorily in a buffered system containing only enzymic extract, homoserine and succinyl-coenzyme A (Expt. 3); the presence of the intermediate under these conditions was confirmed by paper chromatography.

Table 8. The role of succinyl-coenzyme $A$ in cystathionine formation

An 'aged' extract of Escherichia coli strain 7/9 (see text) was incubated for $2.5 \mathrm{hr}$ in buffered homoserine with the stated additions; succinyl-coenzyme A was $1.7 \mathrm{~mm}$ and all other concentrations as in solution $A$. The reaction mixtures were then heated for $2 \mathrm{~min}$. at $100^{\circ}$ and incubation continued for a further $1.5 \mathrm{hr}$ after adding extract of $E$. coli strain 2/2, cysteine and any other substance indicated. CoA, coenzyme A; succinylCoA, succinyl-coenzyme $\mathbf{A}$; - , no addition.

\begin{tabular}{|c|c|c|c|}
\hline \multirow[b]{2}{*}{ Expt. } & \multicolumn{2}{|l|}{ Substance added } & \multirow{2}{*}{$\begin{array}{l}\text { Cystathionine } \\
\text { formed } \\
\text { ( } \mu \mathrm{m} \text {-mole } / \mathrm{mg} . \\
\text { protein) }\end{array}$} \\
\hline & Initially & At $2.5 \mathrm{hr}$ & \\
\hline 1 & Succinate $+\mathrm{CoA}+$ glucose $+\mathbf{A T P}$ & - & 40 \\
\hline 2 & SuccinylCoA + glucose + ATP & - & 160 \\
\hline 3 & SuccinylCoA & Glucose, ATP & 137 \\
\hline 4 & SuccinylCoA & - & $\mathbf{5 2}$ \\
\hline 5 & Succinate + CoA & - & 10 \\
\hline 6 & Glucose + ATP & - & 6 \\
\hline
\end{tabular}

Experiments with a synthetic succinyl derivative of homoserine

The results recorded in the earlier sections indicated that the intermediate in cystathionine synthesis in Escherichia coli was an alkali-labile succinyl derivative of homoserine in which the amino group was still free. The obvious possibility was $O$-succinylhomoserine; no synthesis of this compound had been reported.

Chemical synthesis. No $O$-succinyl derivative of any hydroxyamino acid has so far been described; the synthesis of $O$-acetyl derivatives of serine, threonine, hydroxyproline and tyrosine by reaction of the amino acid with acetic anhydride in glacial acetic acid in the presence of perchloric acid (to prevent $N$-acetylation) was reported by Sakami \& Toennies (1942). This method was later used for the preparation of $\boldsymbol{O}$-acetylhomoserine (Matsuo, Rothstein \& Greenberg, 1956; Grobbelaar \& Steward, 1958). Synthetic material, corresponding in every way to the intermediate formed enzymically, was obtained from homoserine by using succinyl chloride or succinic anhydride as acyl donor and in the presence of perchloric acid to prevent acylation of the amino group. (a) DL-Homoserine (15 mg.) and succinyl chloride $(0.11 \mathrm{ml}$.) were incubated in dioxane containing $0.5 \mathrm{M}$-perchloric acid (1 ml.) for $30 \mathrm{~min}$. at $40^{\circ}$. (b) DL-Homoserine (15 mg.) was mixed with succinic anhydride (600 mg.) and the mixture melted; after adding perchloric acid to a final concentration of about $0.5 \mathrm{M}$, it was kept molten (above $120^{\circ}$ ) for $10 \mathrm{~min}$. In both cases the products were neutralized with potassium carbonate solution and the precipitated potassium perchlorate removed by centrifugation. The supernatant fluids were evaporated to dryness (which removed dioxane when present) and the residues taken up in water. 
Chromatographic properties and purification. The likely impurities (succinic acid, homoserine) were removed by the use of Dowex-1 resin. Homoserine was not retained by the resin and was washed through with water. The succinyl derivative, though not succinic acid, was eluted by $0 \cdot 2 \mathrm{~N}$-acetic acid; succinic acid was eluted by $6 \mathrm{~N}$-formic acid. The separation of homoserine from its succinyl derivative is illustrated in Fig. 7 for a mixture of the two substances. The intermediate compound formed enzymically appeared in the same fractions of the acetic acid eluate (Fig. 7).

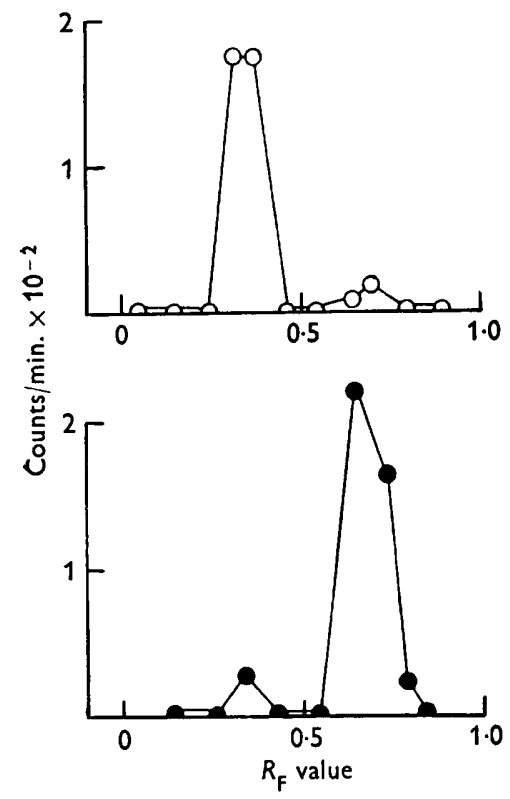

Fig. 6

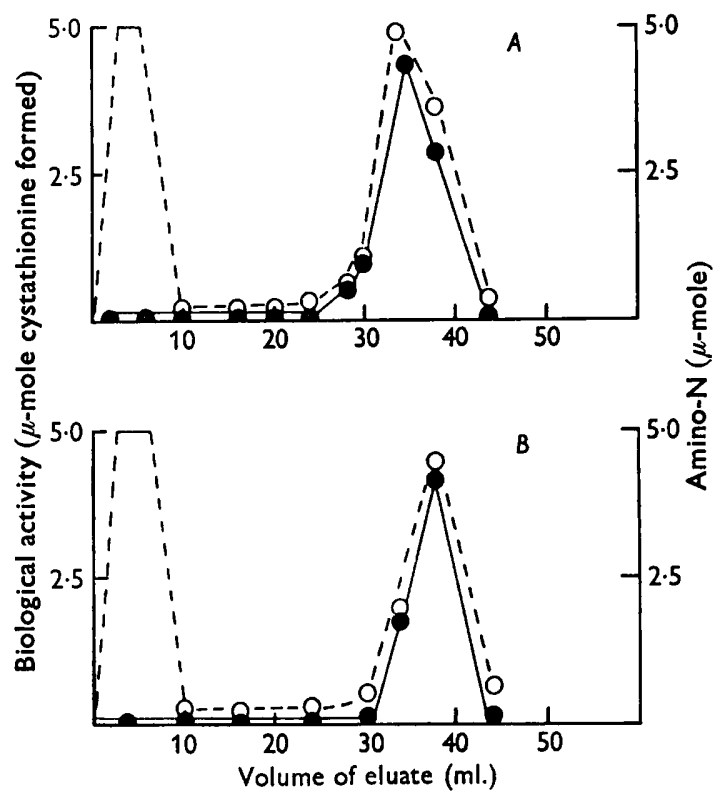

Fig. 7

Fig. 6. Incorporation of radioactive succinate into the intermediate. Reaction mixtures containing the intermediate were obtained by incubating extract of Escherichia coli $7 / 9$ in solution $A$ (minus cysteine) containing $5 \mu \mathrm{C}\left[{ }^{14} \mathrm{C}_{2,3}\right]$-succinate. The material was chromatographed on paper (solvent, $n$-butanol + propionic acid + water) before $(O)$ and after (๑) heating with $\mathrm{N}-\mathrm{HCl}$ for $2 \mathrm{hr}$ at $100^{\circ}$. The chromatograms were scanned directly for radioactivity.

Fig. 7. Chromatography of the intermediate and its synthetic counterpart on Dowex-1 resin. Samples of synthetic $O$-succinylhomoserine (mixed with homoserine) and of enzymic reaction products containing the intermediate were chromatographed on Dowex-1 resin as described in the Methods section. Fractions of the eluate were assayed for amino- $\mathrm{N}\left(--\mathrm{O}_{-}-\right)$and for biological activity (-- - ) in terms of enzymic production of cystathionine in the presence of cysteine. $A$, intermediate formed enzymically; $B$, synthetic $O$-succinylhomoserine.

The compounds formed chemically and enzymically gave identical $\boldsymbol{R}_{\mathrm{F}}$ values when chromatographed on paper with two different solvent systems, $\boldsymbol{R}_{\mathrm{F}} \mathbf{0 \cdot 3 5}$ with $n$-butanol + propionic acid + water and $\boldsymbol{R}_{\mathrm{F}} 0.59$ with $n$-butanol + acetic acid + water; the corresponding values for homoserine itself were $\mathbf{0 \cdot 2 7}$ and $\mathbf{0 \cdot 5 0}$. The two compounds also both gave a yellow-brown colour on heating on paper with ninhydrin; this changed to purple on standing.

Decomposition by acid and alkali. Synthetic material purified by chromato- 
graphy on Dowex-1 resin was assayed for amino-N by the ninhydrin method, with DL-homoserine as standard. A portion was heated at $100^{\circ}$ for $2 \mathrm{hr}$ in $\mathrm{N}-\mathrm{HCl}$ and fractions corresponding to homoserine and succinic acid obtained after treatment with Dowex-1 resin (see above). Homoserine was assayed microbiologically and succinic acid by titration; the latter was not identified specifically. The succinylhomoserine (21.2 $\mu$ mole of amino-N) gave $22.0 \mu$ mole homoserine and $23.7 \mu$ mole of a dibasic acid, presumed to be succinic acid from its chromatographic behaviour and by analogy with the similar acidic product of hydrolysis of the natural intermediate which was shown by isotope technique to be succinic acid. Another portion of the same purified material was incubated at $\mathrm{pH} 11$ for $5 \mathrm{~min}$. at $37^{\circ}$. Chromatography on paper showed that the spot corresponding to the original material had disappeared, but that no homoserine or other ninhydrin-positive compound had been formed. Homoserine (10.5 $\mu$ mole from $21 \cdot 2 \mu$ mole amino-N of the original succinylhomoserine) was, however, formed on acid hydrolysis of the alkali-treated material.

Table 9. Cystathionine formation from synthetic $O$-succinylhomoserine: effect of cysteine concentration

A preparation of $O$-succinylhomoserine ( $1 \mathrm{mM}$ ), purified by chromatography on Dowex-1 resin, was incubated for $3 \mathrm{hr}$ in phosphate buffer containing glucose + ATP (concentrations as in solution $A$ ) with extract of Escherichia coli strain 2/2 (protein, $5 \mathrm{mg} . / 3 \mathrm{ml}$.) and L-cysteine at the concentrations stated.

$\begin{array}{cc}\begin{array}{c}\text { Concn. of } \\ \text { cysteine } \\ (\mathbf{m M})\end{array} & \begin{array}{c}\text { Cystathionine } \\ \text { formed } \\ (\mu \mathrm{m} \text {-mole/mg. } \\ \text { protein) }\end{array} \\ 0 & \\ 0.08 & 2 \\ 0 \cdot 17 & 8 \\ 0.33 & 24 \\ 0 \cdot 83 & 60 \\ 1.66 & 250 \\ \mathbf{3} \cdot 30 & 360 \\ & 420\end{array}$

Biological activity. The synthetic material, like the compound formed enzymically, was converted to cystathionine on incubation with extract of Escherichia coli strain 2/2 and a reaction mixture containing cysteine + glucose + ATP (Table 9); the further addition of homoserine or succinate did not increase the yield. The conversion was quantitative, 21.2 $\mu$ mole (in terms of amino-N) giving $21.0 \mu$ mole cystathionine by microbiological assay (assuming that strain 122/33 responds to both isomers of the standard cystathionine). The elution of biological activity from Dowex-1 resin by $0.2 \mathrm{~N}$-acetic acid corresponded closely with the elution of amino- $\mathrm{N}$ (Fig. 7). Finally, again as with the natural intermediate, biological activity disappeared rapidly on incubation at $\mathrm{pH}$ values above 8 , the effect of increasing $\mathrm{pH}$ value being quantitatively similar (Fig. 5).

The effect of the cysteine concentration on cystathionine formation from the synthetic succinylhomoserine is shown in Table 9 ; at $0.83 \mathrm{~mm}$ the amount of cystathionine formed accounted for about half the cysteine added. 


\section{DISCUSSION}

The evidence for and against cystathionine as an intermediate in the normal pathway of methionine synthesis by competent strains of Escherichia coli was discussed in the Introduction and in a previous paper (Rowbury \& Woods, 1964). The already strong evidence in favour is further strengthened by the present demonstration that strains of $E$. coli contain enzymes which catalyse the formation of cystathionine from precursors indicated by the nutritional requirements of auxotrophs of the methionine series, that is, homoserine and cysteine. The work with cell-free preparations has, however, added succinate to the substrates required. We are indebted to Professor H. L. Kornberg for drawing our attention to the abstract of a communication by himself and others (Davis et al. 1959) relating to the properties of auxotrophs of $\boldsymbol{E}$. coli which require succinate for growth and which first suggested this possibility. An auxotroph that is probably similar in nature was reported by Back \& Westaway (1962). Growth in the presence of methionine represses the formation of the enzymes now shown to catalyse cystathionine synthesis (Rowbury, 1962a) as it does enzymes at other steps of methionine synthesis. There remains little doubt therefore that cystathionine is a normal intermediate.

The discovery that cell-free extracts of two auxotrophs, each unable to produce cystathionine, did so when mixed, indicated that the synthesis occurred in two steps and permitted study of the two reactions without the necessity of attempting the fractionation of extracts of a single strain competent to synthesize cystathionine. With one auxotroph a heat-stable intermediate compound was produced from homoserine and succinate that was converted to cystathionine by the other auxotroph in the presence of cysteine. The first step has been studied in detail and the product identified as $O$-succinylhomoserine. The second step requires further investigation; since glucose and ATP must also be present it is possible that this step is complex and that there may be a further intermediate; when reduced concentrations of cysteine were used, glucose and ATP were not required.

Formation of the intermediate $\boldsymbol{O}$-succinylhomoserine by fresh bacterial extracts was increased by coenzyme $\mathbf{A}$ and that by an 'aged' extract by the addition of a purified preparation (from another source) of an enzyme which catalyses the synthesis of succinyl-coenzyme A. Finally, chemically prepared succinyl-coenzyme A was as effective a substrate as succinate, and, unlike the latter, did not require the additional presence of glucose and ATP. Hence it is probable that the two direct reactants are homoserine and succinyl-coenzyme $\mathrm{A}$, the latter being formed in growing cultures either by the oxidative decarboxylation of $\alpha$-oxoglutarate in the presence of coenzyme A (a step in the tricarboxylic acid cycle) or from free succinate, if any is formed, by the succinyl-coenzyme A synthetase which is also clearly present. With the present enzyme preparations $\alpha$-oxoglutarate replaced succinate, but was less active.

The nature of the reaction, the incorporation of ${ }^{14} \mathrm{C}$ from $\left[{ }^{14} \mathrm{C}_{2,3}\right]$-succinate into the product and the survival in the latter of the free amino group all pointed to the intermediate being an $\boldsymbol{O}$-succinyl derivative of homoserine, a conclusion supported by the identification of homoserine and succinic acid among the products after acidtreatment. The alkali-lability also indicated an $\boldsymbol{O}$-derivative, since $\boldsymbol{O}$-acetyl derivatives of hydroxyamino acids are similarly labile (Sakami \& Toennies, 1942). 
Theoretically two such derivatives are possible, $\boldsymbol{O}$-succinylhomoserine and a diester in which two homoserine residues are in ester link with the two carboxylic acid groups of a single succinate residue; analysis of the acid hydrolysis products of the enzymic intermediate gave a homoserine/succinate ratio of unity, suggesting the monoester. Synthetic material was obtained from homoserine by a method in which $\mathrm{N}$-succinylation was prevented and the presence of a free amino group in the purified product confirmed by the ninhydrin reaction; the same characteristic colour with ninhydrin as observed with the natural intermediate under certain conditions was obtained. Use of succinic anhydride as acylating agent would lead only to $O$-succinylhomoserine, but with succinyl chloride the diester might also be formed. Products obtained by both methods behaved as single (and identical) compounds on chromatography on Dowex-1 resin and it was concluded therefore that the major product in both cases was $O$-succinylhomoserine; the neutral diester would in any case have been expected to have been bound less firmly by the resin than the more acidic $\boldsymbol{O}$-succinylhomoserine.

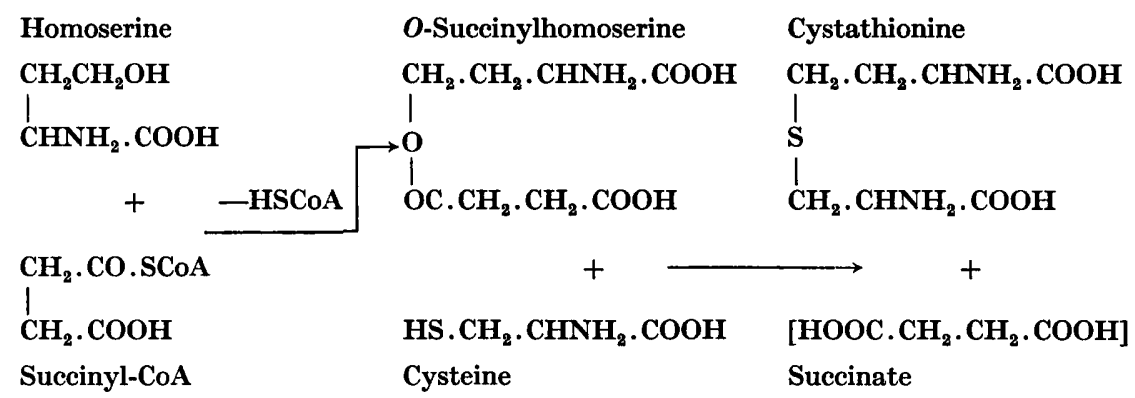

Fig. 8. Pathway of cystathionine synthesis in Escherichia coli.

The intermediate formed enzymically and the synthetic $O$-succinylhomoserine both gave rise to cystathionine when incubated with cysteine and cell-free extracts of the appropriate auxotroph. Their chromatographic properties on paper and Dowex-1 resin were identical, as was also their lability to strong acid and mild alkali; quantitative yields of homoserine and dibasic acid were obtained by acid hydrolysis of the synthetic compound. The product of treatment with mild alkali was not identified, but since it had no free amino group one possibility is that the succinyl residue migrates from the hydroxyl to the amino group; the release of homoserine on subsequent acid hydrolysis supports this view. The intermediate compound retains the amino group function of homoserine but has lost the hydroxyl group function; the presence of an added acidic function is indicated by the fact that it is retained by Dowex-1 resin, whereas homoserine is washed out with water. It is concluded that the natural intermediate is $O$-succinylhomoserine and the steps in cystathionine synthesis may be formulated as in Fig. 8. The name homoserine $O$-transsuccinylase is proposed for the enzyme (present in Escherichia coli $7 / 9$, but not in $E$. coli 2/2) which catalyses the synthesis of $O$-succinylhomoserine.

The present work appears to provide the first case of the natural occurrence of an $\boldsymbol{O}$-succinylated amino acid. $\boldsymbol{O}$-acetylhomoserine is present in Pisum sativum (Grobbelaar \& Steward, 1958) and there is a $N$-succinylation step in the synthesis of lysine by Escherichia coli (Gilvarg, 1960). 
Cystathionine formation in Escherichia coli contrasts sharply with that in animal tissues, where the precursors are homocysteine and serine rather than homoserine and cysteine. The synthetase enzyme in rat liver (Binkley, 1951; Selim \& Greenberg, 1959) requires no accessory substrates or cofactors other than pyridoxal phosphate, and on purification behaves as a single protein. Perhaps surprisingly, no indication of a pyridoxal phosphate requirement has so far been found in the $E$. coli system; it may, however, be tightly bound to one or more of the enzymes, as in the cystathionase of animal tissues (Matsuo \& Greenberg, 1958a, b).

One of us (R.J.R.) is indebted to the Agricultural Research Council for a Studentship held during part of this work, which was aided by grants to the Department from the United States Department of Health, Education and Welfare. We are grateful to Dr L. Fowden for advice on the synthesis of $\boldsymbol{O}$-succinylhomoserine.

\section{REFERENCES}

Back, K. J. C. \& Westaway, E. G. (1962). Studies on a mutant strain of Escherichia coli which requires both methionine and lysine for growth. J. gen. Microbiol. 27, 41.

Binkley, F. (1951). Synthesis of cystathionine by preparations from rat liver. J. biol. Chem. 191, 531.

Bolton, E. T., Cowie, D. B. \& Sands, M. K. (1952). Sulfur metabolism in Escherichia coli. III. The metabolic fate of sulfate sulfur. J. Bact. 63, 309.

Burnham, B. F. (1963). Purification and characterization of succinyl CoA synthetase from Rhodopseudomonas spheroides. Acta chem. scand. 17, Suppl. 123.

Buss, H. R. (1944). The genetics of methionine mutants. Dissertation. Stanford University.

Davis, B. D. (1955). Intermediates in amino acid biosynthesis. Advanc. Enzymol. 16, 247.

Davis, B. D., Kornberg, H. L., Nagler, A., Milleer, P. \& Mingioli, E. (1959). Formation and functions of succinate in Escherichia coli. Fed. Proc. 18, 211.

Gibson, F. \& Woons, D. D. (1960). The synthesis of methionine by suspensions of Escherichia coli. Biochem. J. 74, 160.

Gilvarg, C. (1960). Biosynthesis of diaminopimelic acid. Fed. Proc. 19, 948.

GrobbelaAr, N. \& Steward, F. C. (1958). O-Acetylhomoserine in Pisum. Nature, Lond. $182,1358$.

Guest, J. R., Helleiner, C. W., Cross, M. J. \& Woons, D. D. (1960). Cobalamin and the synthesis of methionine by ultrasonic extracts of Escherichia coli. Biochem. J. 76, 396.

Hirsch, M.-L. \& Cohen, G. N. (1954). Mise en évidence d'un système synthétisant la L-homosérine à la partir de l'acide L-aspartique. Biochim. biophys. Acta, 15, 560.

Matsuo, Y. \& Greenberg, D. M. (1958a). A crystalline enzyme that cleaves homoserine and cystathionine. I. Isolation procedure and some physicochemical properties. J. biol. Chem. 230, 545.

Matsuo, Y. \& Greenberg, D. M. (1958b). A crystalline enzyme that cleaves homoserine and cystathionine. II. Prosthetic group. J. biol. Chem. 230, 561.

Matsuo, Y., Rothstein, M. \& Greenberg, D. M. (1956). Metabolic pathways of homoserine in the mammal. J. biol. Chem. 221, 679.

Moone, S. \& Stein, W. H. (1954). A modified reagent for the photometric determination of amino acids and related compounds. J. biol. Chem. $211,907$.

Rowbury, R. J. (1961). The synthesis of cystathionine by Escherichia coli. Biochem. J. $81,42 \mathrm{P}$.

RowbUry, R. J. (1962a). Control of cystathionine formation in Escherichia coli by methionine. Biochem. J. 82, 24. P.

RowbUry, R. J. (1962b). A succinyl derivative of homoserine as a precursor of methionine in Escherichia coli. J. gen. Microbiol. 28, v.

Rowbury, R. J. \& Woods, D. D. (1961 $a)$. Further studies on the repression of methionine synthesis in Escherichia coli. J. gen. Microbiol. 24, 129. 
Rowbury, R. J. \& Woods, D. D. (1961 b). Repression of cystathionase production in Escherichia coli. Biochem. J. 79, 36 P.

Rowbury, R. J. \& Woods, D. D. (1964). Repression by methionine of cystathionase formation in Escherichia coli. J. gen. Microbiol. 35, 145.

Sakami, W. \& Toennies, G. (1942). The investigation of amino acid reactions by methods of non-aqueous titrimetry. II. Differential acetylation of hydroxyl groups, and a method for the preparation of $O$-acetyl derivatives of hydroxyamino acids. J. biol. Chem. 144, 203.

Selim, A. S. M. \& Greenberg, D. M. (1959). An enzyme that synthesizes cystathionine and deaminates L-serine. J. biol. Chem. 234, 1474.

Simon, E. J. \& Shemin, D. (1953). The preparation of $S$-succinyl coenzyme A. J. Am. chem. Soc. 75, 2520.

Sмiтн, D. A. (1961). Some aspects of the genetics of methionineless mutants of Salmonella typhimurium. J. gen. Microbiol. 24, 335.

WALL, J. S. (1953). Simultaneous separation of purines, pyrimidines, amino acids, and other nitrogenous compounds by ion exchange chromatography. Analyt. Chem. 25, 950.

Wijesundera, S. \& Woods, D. D. (1953). Cystathionine in relation to methionine synthesis by Bacterium coli. J. gen. Microbiol. 9, iii.

WiJesundera, S. \& Woods, D. D. (1962). The catabolism of cystathionine by Escherichia coli. J. gen. Microbiol. 29, 353. 